\title{
Body mass index in early-pregnancy and selected maternal health outcomes: Findings from two cohorts in Bangladesh
}

\author{
Monjur Rahman ${ }^{1}$, Syed Moshfiqur \\ Rahman², Jesmin Pervin', Shaki \\ Aktar $^{1}$, Shams El Arifeen ${ }^{1}$, Anisur \\ Rahman ${ }^{1}$

\begin{abstract}
${ }^{1}$ Maternal and Child Health Division, International Centre for Diarrhoeal Disease Research, Bangladesh

${ }^{2}$ International Maternal and Child Health, Department of Women's and Children's Health, Uppsala University, Uppsala, Sweden
\end{abstract}

\begin{abstract}
Background Maternal nutrition is one of the most influential factors that affect the health of the mother and her offspring and remains a significant public health challenge globally. There is a lack of studies evaluating the trends of maternal nutrition and its impact on the burden of pregnancy complications from low-income countries, including Bangladesh. We aimed to determine the burden of early-pregnancy nutrition status based on body mass index (BMI), and the associations of nutritional status with pregnancy-induced hypertension (PIH), cesarean section (CS) delivery, perineal tear and postpartum hemorrhage (PPH) in a rural area in Bangladesh.
\end{abstract}

Methods This prospective study analyzed data from two cohorts: the Maternal, Neonatal, and Child Health (MNCH) project carried out from January 2008 to June 2010, and the Preterm and Stillbirth Study, Matlab (PreSSMat) conducted from October 2015 to March 2018. In total, information of 9287 women who gave birth from the two cohorts was available for analysis. Early-pregnancy BMI was categorized into underweight, normal-weight, and overweight groups. The change in the burden of malnutrition between two cohort periods and the associations between women's BMI and maternal health outcomes were presented in odds ratios (ORs) with their 95\% confidence interval (CI).

Results Between the two cohort periods, the prevalence of underweight decreased from $17.5 \%$ to $15.4 \%$, and overweight increased from $10.8 \%$ to $20.9 \%$. The risk of being overweight in pregnant women was about two times ( $\mathrm{OR}=2.19 ; 95 \% \mathrm{CI}=1.94-2.46)$ higher in the PreSSMat cohort than in the MNCH cohort. After multivariate-adjustment for socio-demographic factors, the pooled ORs of PIH, CS delivery, perineal tear, and PPH were 2.41 (95\% CI =1.95-2.99), 2.12 (95\% CI =1.86-2.41), 2.46 (95\% CI $=1.54-3.92)$, and 1.68 (95\% CI $=1.12-2.53)$, respectively, in women with overweight compared to the normal-weight group.

Conclusions The results confirmed the existence of a double burden of malnutrition in rural women in Bangladesh. Women with overweight had an increased risk of selected pregnancy complications. The findings call for the adoption of appropriate prenatal counseling and preparedness tailored to women's nutritional status to prevent possible adverse health outcomes. 
Maternal nutrition is one of the most influential factors that affect the health of mothers and their offspring [1,2]. In population-based studies, nutrition status is commonly assessed by body mass index (BMI) that is calculated by weight in kilograms divided by the square of the height in meters $\left(\mathrm{kg} / \mathrm{m}^{2}\right)$. Due to immediate-, short-, and long-term health effects on mothers and their children, both underweight $($ BMI $<18.5)$ and overweight $(\mathrm{BMI} \geq 25.0)$ are recognized as important public health issues in all countries across the world $[3,4]$. The achievement of the Sustainable Development Goals (SDGs) 2 and 3, ending all forms of malnutrition and ensuring healthy lives and well-being for all ages, respectively, rely on how a country adopts strategies to prevent malnutrition and its associated health impacts [5].

It is estimated that about 153.8 million women of reproductive age have been suffering from underweight worldwide [6]. Almost half of these women live in South Asia, particularly in Bangladesh, India, and Pakistan $[7,8]$. Globally, the prevalence of maternal underweight has declined from $11.6 \%$ in 2000 to $9.7 \%$ in 2016 [6]. In Bangladesh, the proportion of women with underweight decreased from 52\% in 1996 to $19 \%$ in 2014 [9]. Although the data indicate a substantial decline in prevalence, the current burden is still high compared to many low- and middle-income countries.

At the other end of the malnutrition spectrum, overweight has been an alarming health concern in high-income countries for decades $[10,11]$. Due to rapid economic development, many low-income countries are now in a phase of nutrition and epidemiologic transitions that have led to an increase in overweight or obesity in women of reproductive age at a population level [12]. The proportion of overweight has increased from 29\% in 1980 to 38\% in 2013, globally [13]. In Bangladesh, the burden of overweight also increased from 3\% in 1996 to 24\% in 2014 [9].

The associations of high BMI with adverse maternal health outcomes in pregnancies are well documented from high-income settings [14]. Overweight in pre- or early-pregnancy is associated with high risks of pregnancy-induced hypertension (PIH), and cesarean section (CS) delivery [15-19]. Studies also have investigated the associations between BMI and other maternal morbidities, including perineal tear [20$23]$ and postpartum hemorrhage (PPH) $[17,24,25]$. However, the reported associations are inconsistent. A few studies have reported that overweight is protective against perineal trauma [20,22], while others have suggested high risk for perineal injury $[21,23]$. Several studies, mainly from high-income countries, have investigated the impact of obesity on PPH and have reported a small $[24,26]$ to a moderate increase of PPH odds $[27,28]$ in obese women compared to the normal-weight women. However, few study findings did not support the associations $[29,30]$.

Studies on trends in maternal malnutrition and its association with health outcomes during pregnancy are scarce from low-income countries. The available studies are cross-sectional [17], and based on data from the National Demographic Health Surveys, or hospital-based information with small sample size [31-33]. There are also inconsistencies in reported associations between maternal BMI and the above pregnancy complications, thus warranting more evaluations. Therefore, our primary objective was to evaluate the associations between early-pregnancy BMI and selected maternal health outcomes based on two well-characterized cohorts conducted in rural Matlab, Bangladesh. Further, we also assessed the burden of malnutrition in women in the early gestational period over time.

\section{METHODS}

\section{Study settings, design and study subjects}

The study site is located in Matlab Upazila in Chandpur district, Bangladesh. International Centre for Diarrhoeal Disease Research, Bangladesh (icddr,b) has been running a Health and Demographic Surveillance System (HDSS) in a population of about 220000 since 1966. This study was conducted in half of the HDSS area, where icddr,b provides health services to women of reproductive age and the children below five years. The study area has four administrative blocks, and each block has a health sub-center where midwives provide 24-hour maternal and child health services. A hospital run by icddr,b, and located in Matlab Township, provides support as a referral facility for women and children from the community and sub-centers. However, the Matlab Hospital provides only basic obstetric care by nurses and medical officers. Due to the lack of cesarean facility, a woman who requires CS needs a referral to a public health facility or private clinic with comprehensive obstetric care provision.

In the present paper, we used available information from two cohorts - the Maternal, Neonatal, and Child Health $(\mathrm{MNCH})$ project, and the Preterm and Stillbirth Study, Matlab (PreSSMat). In addition to this, the 
routine data collected by the HDSS was also used. The $\mathrm{MNCH}$ project aimed to strengthen the existing maternal and child health services along the continuum of pregnancy, delivery, and postpartum periods. The study was carried out between January 2008 and June 2010 [34]. The purpose of the PreSSMat project was to establish a cohort to collect related information to understand the biological determinants of preterm births [35]. The PreSSMat was conducted between October 2015 and March 2018.

In the current study, the women were considered eligible for analyses if the following criteria were met: (i) the women were identified as pregnant by the HDSS, (ii) the pregnant women provided consents for participation in the MNCH or PreSSMat study, and (iii) the anthropometric measurements were available before 20 gestation weeks (GWs) of age.

\section{Data collection}

The exposure and outcome information was obtained from the MNCH and PreSSMat databases, while the covariate information was extracted from the HDSS databases. The HDSS recorded socio-demographic characteristics and updated the information through household visits of community health workers (CHWs) every two-month. During household visits in the study area, CHWs asked women of reproductive age if they had missed their periods. Women who reported menstrual period being at least two weeks overdue were invited to take a urine pregnancy test. Women with positive pregnancy test results were requested to attend the respective sub-center or Matlab Hospital for further assessment by ultrasound. A woman, who provided her consent for participation in the study, was invited to visit to undergo four antenatal care services and use icddr,b facilities for delivery, and postpartum care. Medical history, physical examination, and clinical data collection were similar for both cohorts and were collected during each contact.

\section{Exposure}

The exposure variable was the women's BMI, which was calculated from the mother's weight and height collected before $20 \mathrm{GWs}$ of age. Maternal weight was measured by using a bathroom scale (SECA, Uniscale, Hamburg, Germany) with a precision of $100 \mathrm{~g}$. Height was measured with a locally made wooden scale (precision $0.1 \mathrm{~cm}$ ). The BMI was categorized as underweight $\left(\mathrm{BMI}<18.5 \mathrm{~kg} / \mathrm{m}^{2}\right.$ ), normal-weight $\left(B M I=18.5-24 \mathrm{~kg} / \mathrm{m}^{2}\right)$, and overweight $\left(\mathrm{BMI} \geq 25 \mathrm{~kg} / \mathrm{m}^{2}\right)$. Overweight group is further divided into preobese $\left(\mathrm{BMI}=25-29 \mathrm{~kg} / \mathrm{m}^{2}\right.$ and obese $\left(\mathrm{BMI} \geq 30 \mathrm{~kg} / \mathrm{m}^{2}\right)[36]$.

\section{Outcomes}

We evaluated the selected maternal health outcomes during pregnancy, such as PIH, CS, perineal tear, and PPH. In the MNCH and PreSSMat cohorts, PIH was classified as chronic, gestational, preeclampsia/ eclampsia, or super-imposed preeclampsia with chronic hypertension. Chronic hypertension was defined when the woman had high blood pressure (systolic blood pressure $\geq 140 \mathrm{~mm} \mathrm{Hg}$ or diastolic blood pressure $\geq 90 \mathrm{~mm} \mathrm{Hg}$ ) before pregnancy or early in pregnancy (before $20 \mathrm{GWs}$ ) and continued to have it after delivery. If a previously normotensive woman developed high blood pressure with no protein in urine after 20 GWs, it was considered to be gestational hypertension. Preeclampsia was defined as gestational hypertension with proteinuria $2+$ or higher on dipstick testing. Eclampsia was considered as the onset of convulsion or seizures in a woman with preeclampsia. Super-imposed preeclampsia with chronic hypertension was identified if the diagnosed women had been with chronic hypertension already before the pregnancy and then developed preeclampsia during pregnancy. The mode of delivery was classified as vaginal or CS delivery. A perineal tear was defined as laceration of the skin, which extends beyond fourchette, perineal skin, and vaginal mucosa - to perineal muscles and fascia, or tear of the external of the anal sphincter. A first-degree perineal tear was defined as an injury to the vaginal mucosa and connective tissue. A second-degree perineal tear was an injury to the perineum involving vaginal mucosa and perineal muscles without involving the anal sphincter. When the injury involved the anal sphincter complex, it was considered to be a third-degree tear. PPH was defined as the loss of more than $500 \mathrm{ml}$ of blood within the first 24 hours following childbirth. The attending midwife or medical officer diagnosed PPH by estimating the number of pads soaked by blood in 24 hours of delivery or observing if a pad or the cloths soaked within 5 minutes or by the constant trickling of blood [37].

\section{Covariates}

The mother's age was calculated by subtracting the date of birth from the date of the last menstrual period (LMP) and was expressed in years. Parity was defined as the number of live birth or stillbirth born be- 
fore the current pregnancy. Maternal education was measured by the number of completed years in a formal school. We assessed the wealth status by generating scores through principal components analysis. It was based on the ownership of household assets, such as consumer items (eg, television, almirah, mobile phone, and other valuable items), dwelling characteristics (wall and roof materials), type of drinking water, and toilet facilities. The generated scores were then divided into quintiles, where one represented the poorest and five, the wealthiest.

\section{Statistical analysis}

Descriptive statistics such as frequency, mean (Standard deviation, SD), median, and proportions were used to characterize the study participants. In the analyses, maternal age was categorized into $<20,20-24,25-29$, or $\geq 30$ years, parity into $0,1-2$, or $\geq 3$, mother's education into no education ( 0 years), primary ( $1-5$ years), or secondary or higher ( $\geq 6$ years). Associations of available covariates, exposure and outcomes between two cohorts were assessed by $\chi^{2}$ tests. We graphically presented the trend of nutritional status by BMI and the outcomes. The changes in proportions of women with underweight and overweight compared to the women with normal-weight between $\mathrm{MNCH}$ and PreSSMat cohorts were assessed by multinomial logistic regression analysis. The associations between early-pregnancy BMI and maternal health outcomes were assessed by using binary logistic regression separately for each cohort. Covariates associated with exposure and outcome at $P<0.2$ were included in the logistic regression analysis, while a backward stepwise approach was used to identify those independently associated with the outcome of interest $(P<0.05)$ to keep in the final multivariate model. Furthermore, the effect estimates from the multivariate-adjusted regression models in each cohort were pooled to obtain the summary risk estimates with the use of an inverse variance-weighted meta-analysis. We used both random- and fixed-effect models. However, we presented the result from the fixed-effect model due to the observed $P$ value of heterogeneity at $>0.1$. The results of regression analyses were presented by crude and adjusted odds ratios (ORs) with their 95\% confidence intervals (CI). We used Stata version 13 for all statistical analyses (StataCorp, College Station, TX, USA).

\section{Ethical consideration}

Ethical approval was obtained from the Research and Ethical Review Committees of the International Centre for Diarrhoeal Disease Research, Bangladesh (icddr,b) for both of the cohort studies. All the participants provided informed written consent before

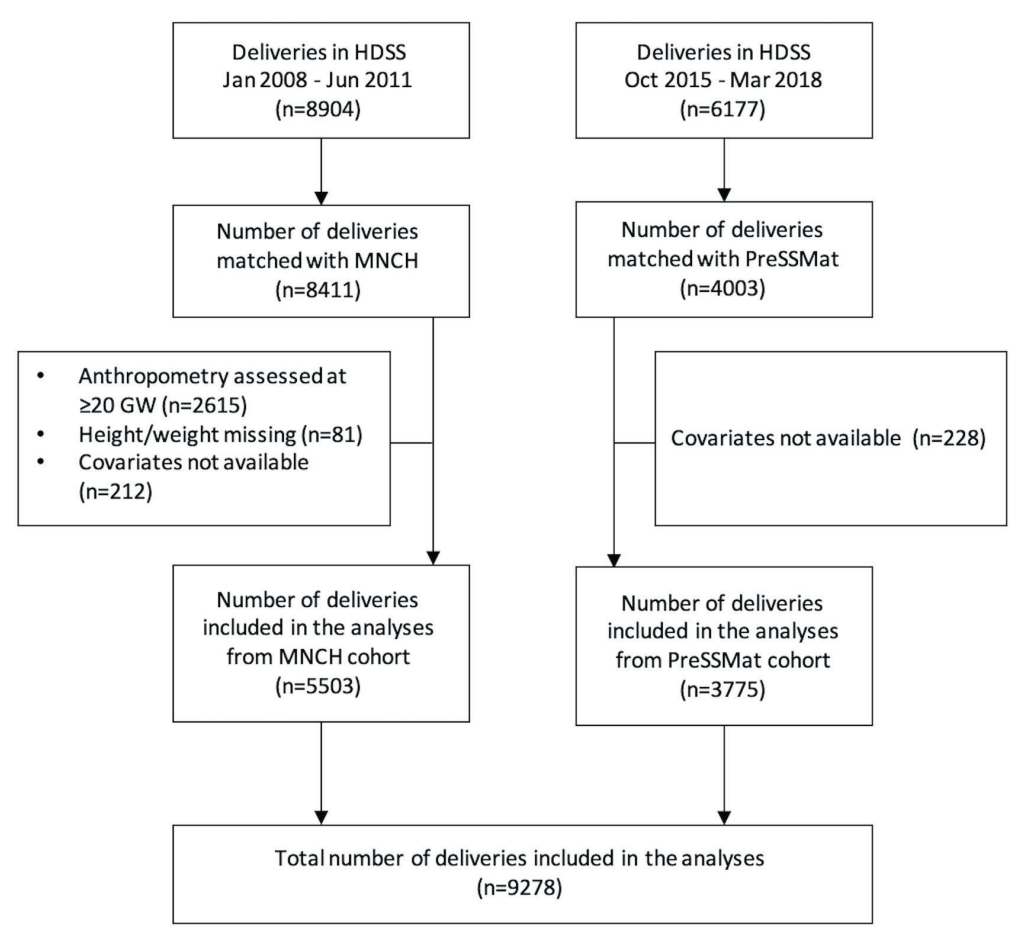

Figure 1. Study profile. HDSS, health and demographic surveillance system; $\mathrm{MNCH}$, maternal, neonatal, and child health, PreSSMat, preterm and stillbirth study, Matlab. study enrollment, and each individual was assigned an anonymous participant identification code.

\section{RESULTS}

Out of 15081 deliveries recorded in the HDSS databases, 12414 (82.3\%) deliveries were available in the $\mathrm{MNCH}$ and PreSSMat databases, where women provided consents for participation. After excluding the pregnant women who appeared in the facilities at $\geq 20 \mathrm{GWs}$ for the first antenatal care service, and the women with missing covariate information, 9278 (5503 from MNCH and 3775 from PreSSMat) deliveries were available and thus included in the analysis (Figure 1). The mean (SD) gestational ages of weight measurements were 16.6 (1.1) and 12.9 (1.9) weeks for the MNCH and PreSSMat cohorts, respectively.

The background characteristics of the study women from both cohorts are presented in Table 1. The mean ages of women in the $\mathrm{MNCH}$ and PreSSMat co- 
horts were $25.8(\mathrm{SD}=5.9)$, and 25.4 $(\mathrm{SD}=5.9)$ years. The mean and median years of school attendance were $6.2(\mathrm{SD}=3.6)$ and seven years, respectively, for the MNCH cohort. For the PreSSMat cohort, the figures were 7.5 $(\mathrm{SD}=3.7)$ and eight years, respectively. Overall, compared to the $\mathrm{MNCH}$ cohort women, the women from the PreSSMat cohort had higher age, lower parity, and higher education attainment by years of school attendance (Table 1 ).

The mean weight and height of the women in $\mathrm{MNCH}$ cohort were 47.8 $(\mathrm{SD}=7.6) \mathrm{kg}$, and $150.5(\mathrm{SD}=5.7) \mathrm{cm}$, respectively, whereas these were 50.9 $(\mathrm{SD}=9.0)$ and $151.8(\mathrm{SD}=5.2)$ in the PreSSMat cohort, respectively. The mean BMI was $21.1(\mathrm{SD}=3.1)$ and 22.1 $(\mathrm{SD}=3.6) \mathrm{kg} / \mathrm{m}^{2}$ in $\mathrm{MNCH}$ and PreSSMat cohorts. Due to a small number of women with obesity (53 in $\mathrm{MNCH}$, 109 in PreSSMat), we merged the preobese and obese groups as an overweight group. Maternal nutritional status, assessed by BMI, indicated that the proportion of underweight women decreased marginally - from $17.5 \%$ in the $\mathrm{MNCH}$ cohort to $15.4 \%$ in the PreSSMat cohort. In contrast, the proportion of overweight increased remarkably from $10.8 \%$ to $20.9 \%$ between the two study periods (Figure 2).

Figure 3 presents the proportion of maternal health outcomes in the two cohorts. The CS rate was very high in this population. The rate significantly increased from about $18 \%$ in the $\mathrm{MNCH}$ cohort to about $48 \%$ in the PreSSMat cohort (Figure 3).

The associations between nutritional status during early-pregnancy and the available covariates are presented by each cohort (Table S1 in the Online Supplementary Document). In both cohorts, all the covariates were found to be significantly associated with nutritional status during early pregnancy (Table S1 in the Online Supplementary Document).

We assessed the associations of maternal health outcomes with available covariates in MNCH and PreSSMat cohorts (Table S2 and S3 in the Online Supplementary Document). The associations with those socio-demographic
Table 1. Background characteristics of study participants in the two cohorts in Matlab, Bangladesh

\begin{tabular}{|c|c|c|c|c|}
\hline & ALL PARTICIPANTS & Ммсн & PreSSMat & \\
\hline & $N=9278$ & $\mathrm{n}=5503$ & $\mathrm{n}=3775$ & $P$-value** \\
\hline \multicolumn{5}{|c|}{ Maternal age (year), n (\%): } \\
\hline$<20$ & $1730(18.6)$ & $1035(18.8)$ & $695(18.4)$ & 0.018 \\
\hline $20-24$ & $2997(32.3)$ & $1837(33.4)$ & $1160(30.7)$ & \\
\hline $25-29$ & $2361(25.4)$ & $1378(25.0)$ & $983(26.0)$ & \\
\hline$\geq 30$ & $2190(23.6)$ & $1253(22.8)$ & $937(24.8)$ & \\
\hline \multicolumn{5}{|l|}{ Parity, n (\%): } \\
\hline 0 & $3311(35.7)$ & $1924(35.0)$ & $1387(36.7)$ & $<0.001$ \\
\hline 1 & $5197(56.0)$ & $3053(55.5)$ & $2144(56.8)$ & \\
\hline$\geq 2$ & $770(8.3)$ & $526(9.6)$ & $244(6.5)$ & \\
\hline \multicolumn{5}{|c|}{ Education (year), n (\%): } \\
\hline 0 & $1124(12.1)$ & $717(13.0)$ & $407(10.8)$ & $<0.001$ \\
\hline $1-5$ & $2186(23.6)$ & $1528(27.8)$ & $658(17.4)$ & \\
\hline$\geq 6$ & $5968(64.3)$ & $3258(59.2)$ & $2710(71.8)$ & \\
\hline \multicolumn{5}{|c|}{ Wealth quintile, n (\%): } \\
\hline 1-Poorest & $1429(15.4)$ & $822(14.9)$ & $607(16.1)$ & 0.470 \\
\hline 2 & $1633(17.6)$ & $961(17.5)$ & $672(17.8)$ & \\
\hline 3 & $1829(19.7)$ & $1079(19.6)$ & $750(19.9)$ & \\
\hline 4 & $2064(22.2)$ & $1243(22.6)$ & $821(21.7)$ & \\
\hline 5-Wealthiest & $2323(25.0)$ & $1398(25.4)$ & $925(24.5)$ & \\
\hline
\end{tabular}

MNCH - Maternal, Neonatal, and Child Health, PreSSMat - Preterm and Stillbirth Study, Matlab

* Significance levels by $\chi^{2}$ tests for background characteristics between $\mathrm{MNCH}$ and PreSSMat cohort.

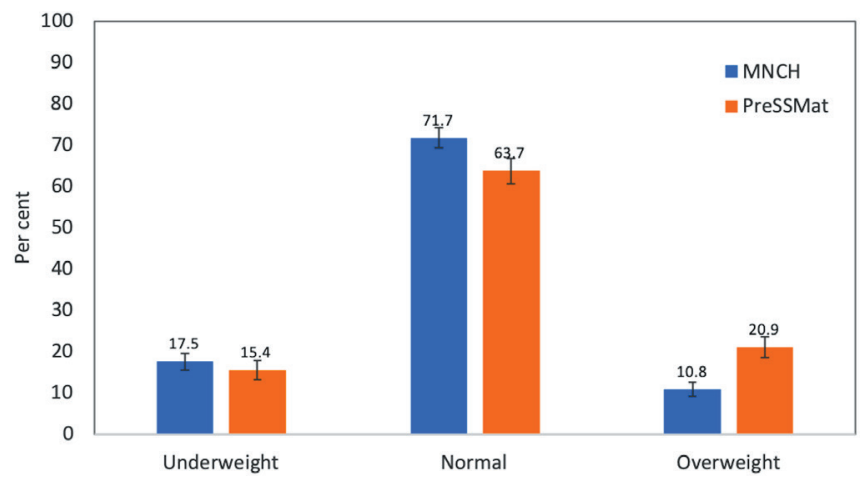

Figure 2. Change in prevalence of underweight and overweight pregnant women. MNCH, maternal, neonatal, and child health; PreSSMat, preterm and stillbirth study, Matlab. Error bars represent 95\% confidence interval bands.

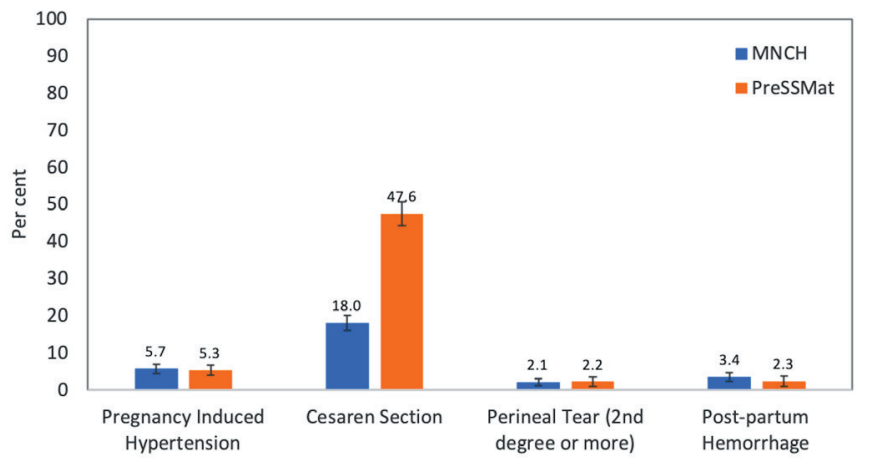

Figure 3. Proportion of maternal outcomes by cohort. MNCH, maternal, neonatal and child health; PreSSMat, preterm and stillbirth study, Matlab. Error bars represent 95\% confidence interval bands. 
factors differ between cohorts. Based on the criteria to determine the potential confounders in the analysis plan, we assessed the covariates' associations with exposures and outcomes for inclusion in the multivariate logistic regression model (Table S4 Online Supplementary Document).

In the multinomial logistic regression, we did not observe any change in underweight (OR =0.99, 95\% $\mathrm{CI}=0.88-1.11$ ) between the two cohorts. However, the risk of the women being overweight was about two times higher $(\mathrm{OR}=2.19,95 \% \mathrm{CI}=1.94-2.46)$ in the PreSSMat cohort compared to those in the MNCH cohort.

Maternal overweight was found associated with increased risks of PIH, CS delivery, and perineal tear in both cohorts (Table 2 and Table 3). However, for PPH, the risk was only observed in the MNCH cohort (Table 2). The women in the underweight group were less likely to have CS in the MNCH cohort, and no association with other maternal outcomes was observed (Table 2). In the PreSSMat cohort, decreased odds of PIH and CS deliveries were observed in women with underweight (Table 3).

Table 2. Associations between early-pregnancy body mass index and maternal health outcomes in the MNCH cohort in Matlab, Bangladesh

\begin{tabular}{|c|c|c|c|c|c|c|c|}
\hline & \multicolumn{2}{|c|}{ Pregnancy-Induced hypertension } & \multicolumn{2}{|l|}{ Cesarean section } & \multicolumn{2}{|c|}{ Perineal tear (2 $2^{10}$ degree OR MOre) ${ }^{*}$} & Postpartum hemorrhage* \\
\hline BMI category $\dagger$ & OR $(95 \% \mathrm{CI})$ & $\mathrm{aOR}(95 \% \mathrm{CI}) \ddagger$ & OR $(95 \% \mathrm{CI})$ & $\mathrm{aOR}(95 \%$ & OR $(95 \% \mathrm{CI})$ & aOR $(95 \% \mathrm{CI}) \mid$ & OR (95\% CI)G \\
\hline Underweight & $78(0.55$ & $0.78(0.55$ & $0.58(0.47-0.72)$ & $0.56(0.45-0.70)$ & $1.11(0.65-1.88)$ & $1.01(0.60-1.73)$ & $0.90(0.58-1.39)$ \\
\hline Normal-weight** & 1 & 1 & 1 & 1 & 1 & 1 & 1 \\
\hline
\end{tabular}

$\mathrm{BMI}$ - body mass index, OR - odds ratio, aOR - adjusted odds ratio; $\mathrm{CI}$ - confidence interval

*Analysis limited to women with vaginal delivery

$\dagger$ BMI category: underweight (<18.5 kg/m2), normal-weight (18.5-24 kg/m2), and overweight ( $\geq 25 \mathrm{~kg} / \mathrm{m} 2)$

$\ddagger$ Adjusted for maternal education

§Adjusted for maternal parity, education and wealth quintile

|Adjusted for maternal parity

INo covariate associated with exposure and outcome, thus crude OR is presented

***eference category.

Table 3. Associations between early-pregnancy body mass index and maternal health outcomes in the PreSSMat cohort in Matlab, Bangladesh

\begin{tabular}{|c|c|c|c|c|c|c|c|}
\hline & \multicolumn{2}{|c|}{ Pregnancy-Induged hypertension } & \multicolumn{2}{|c|}{ Cesarean section } & \multicolumn{2}{|c|}{ Perineal tear (2no degree or more) ${ }^{*}$} & \multirow{2}{*}{$\begin{array}{c}\text { Postpartum hemorrhage } \\
\text { OR (95\% CI)पI }\end{array}$} \\
\hline BMI category $\dagger$ & OR $(95 \% \mathrm{CI})$ & $\mathrm{aOR}(95 \% \mathrm{CI}) \ddagger$ & OR (95\% CI) & $\mathrm{aOR} *(95 \% \mathrm{CI}) \S$ & OR $(95 \% \mathrm{CI})$ & aOR $(95 \% \mathrm{CI}) \mid$ & \\
\hline Underweight & $53(0.31-0.92)$ & $47(0.27-0.81)$ & $74(0.61-0.89)$ & $0.69(0.57-0.84)$ & $1.12(0.50-2.50)$ & $0.97(0.43-2.20)$ & $1.85(0.94-3.64)$ \\
\hline Normal-weight** & 1 & 1 & 1 & 1 & 1 & 1 & 1 \\
\hline
\end{tabular}

BMI - body mass index, OR - odds ratio, aOR - adjusted odds ratio, CI - confidence interval

*Analysis limited to women with vaginal delivery.

$\dagger$ BMI category: underweight $\left(<18.5 \mathrm{~kg} / \mathrm{m}^{2}\right)$, normal-weight $\left(18.5-24 \mathrm{~kg} / \mathrm{m}^{2}\right)$, and overweight $\left(\geq 25 \mathrm{~kg} / \mathrm{m}^{2}\right)$

$\ddagger$ Adjusted for maternal parity and wealth quintile.

$\S$ Adjusted for maternal parity, age and wealth quintile.

Adjusted for maternal age.

IINo covariate associated with exposure and outcome, thus crude OR is presented.

** Reference category.

The meta-analyses demonstrated that compared to the normal-weight group, the pooled adjusted ORs in the overweight women group for PIH, CS, perineal tear and PPH were 2.41 (95\% CI=1.95-2.99), 2.12 (95\% CI $=1.86-2.41), 2.46$ (95\% CI = 1.54-3.92), and 1.68 (95\% CI=1.12-2.53), respectively (Table 4). The women in the underweight group were less likely to have PIH $(\mathrm{OR}=0.67,95 \% \mathrm{CI}=0.50-0.90)$ and CS deliveries $(\mathrm{OR}=0.63,95 \% \mathrm{CI}=0.55-0.73)$ only (Table 4$)$.

\section{DISCUSSION}

Based on the data from two prospective cohorts, the present study has found the co-existence of underweight and overweight pregnant women, and the associations of high early-pregnancy BMI with increased risk of adverse maternal health outcomes in a rural area in Bangladesh. We observed no changes in the prevalence of underweight. However, the burden of overweight increased about two times in the later cohort than the earlier one. Compared to the women in the normal-weight group, we found the overweight women had increased risk of PIH, CS delivery, perineal tear, and PPH. 
Table 4. Associations between early-pregnancy body mass index category and maternal health outcomes by meta-analyses based on the effect estimated in multivariable-adjusted regression in the MNCH and PreSSMat cohorts in Matlab, Bangladesh

\begin{tabular}{|c|c|c|c|c|}
\hline BMI CATEGORY* & Pregnancy-Induced hypertension & Cesarean section & Perineal tear ( $2^{\text {Mo }}$ degree or more) $†$ & Postpartum hemorrhage† \\
\hline & OR $(95 \% \mathrm{CI}) \ddagger$ & OR $(95 \% \mathrm{CI}) \neq$ & OR $(95 \% \mathrm{CI}) \ddagger$ & OR $(95 \% \mathrm{CI}) \neq$ \\
\hline Underweight & $0.67(0.50-0.90)$ & $0.63(0.55-0.73)$ & $1.00(0.64-1.56)$ & $1.11(0.77-1.61)$ \\
\hline Normal-weight§ & 1 & 1 & 1 & 1 \\
\hline Overweight & $2.41(1.95-2.99)$ & $2.12(1.86-2.41)$ & $2.46(1.54-3.92)$ & $1.68(1.12-2.53)$ \\
\hline
\end{tabular}

BMI - body mass index, OR - odds ratio, CI - confidence interval

*BMI category: underweight $\left(<18.5 \mathrm{~kg} / \mathrm{m}^{2}\right)$, normal-weight $\left(18.5-24 \mathrm{~kg} / \mathrm{m}^{2}\right)$, and overweight $\left(\geq 25 \mathrm{~kg} / \mathrm{m}^{2}\right)$.

$\uparrow$ Analysis limited to women with vaginal delivery.

¥Pooled adjusted odds ratio using fixed effect model.

§Reference category.

The double burden of malnutrition observed in our study is consistent with studies conducted in other South Asian countries, including India and Pakistan [38]. Several studies have reported that both underweight and overweight are prevalent in the Bangladeshi population. A recent cross-sectional survey of women of reproductive ages reported the prevalence of underweight and overweight to be 32\% and 14\% in 2007; and 21\% and 26\% in 2014, respectively [31]. Although the burden of overweight was similar, the proportion of underweight was lower in our study sample. This variation may have arisen due to anthropometric measurements after delivery in the survey study. The Bangladesh Demographic and Health Survey (BDHS) has reported that the proportion of underweight among the pregnant population is 18\%, consistent with our finding [9].

There is a scarcity of studies evaluating the association of maternal pre- or early-pregnancy overweight with pregnancy complications in low-income countries, including Bangladesh $[17,32,38]$. Thus far, only one study has used information from the BDHS, in this case, from the years 2011 and 2014 to report associations between maternal BMI and increased risks of hypertension and CS [32]. However, that study had several limitations, the BMI of women were assessed at the survey interview, and the outcome information was based on the data collection by five years recall [32]. Overweight has consistently been reported to be associated with a high risk of PIH and CS deliveries. The estimated risk increases observed at two to three times higher than the women with normal-weight in those studies $[17,39,40]$ are comparable with the risks observed in our study.

The reported relationships between overweight and perineal tear and postpartum hemorrhage are inconsistent. Only a few studies are available that evaluated the impact of obesity on perineal trauma. However, in contrast to our findings, the studies reported obesity as a protective factor against both mild and severe forms of perineal injury $[20,22]$. The risk estimate of perineal tear in the study is consistent with the studies conducted in Slovenia and Saudi Arabia [21,41]. A recent hospital-based cohort study conducted in California, US, reported a small but significant increase of PPH (OR $=1.06,95 \% \mathrm{CI}=1.04-1.08)$ [24]. Another study that used the birth registry data in Sweden also reported a similar risk increase for $\mathrm{PPH}(\mathrm{OR}=1.08,95 \% \mathrm{CI}=1.04-1.11)$ in overweight women who delivered vaginally [26]. The observed OR in our study was similar to the studies conducted in New Zealand and the UK, which reported the estimated ORs for PPH to be 2.11 (95\% CI=1.84-2.89) and 1.4 (99\% CI: 1.3-1.6), respectively $[27,28]$.

The increased maternal overweight trends in our study may be explained by consistent economic growth over the last decade in Bangladesh. It is estimated that the country's per-capita GDP increased from US\$ 780 in 2009-10 to US\$ 1544 in the 2016-2017 fiscal year [42]. There are also changes in food habits, social, and lifestyle patterns, leading to more physical inactivity in rural and urban areas. Even with the rapid social changes and economic development, the distribution of wealth is unequal within the population. This inequality explains the sizable proportion of undernourished women in this rural community and other parts of the country $[31,43]$.

The mechanisms behind the association of malnutrition with morbidities in pregnancies are not fully elucidated. Hypertensive disorders due to obesity are possibly mediated through activation of the sympathetic nervous system, and renal impairment, and also by inflammatory mediators [44-46]. Other possible mechanisms linked with hypertension in pregnancy are oxidative stress, insulin resistance, and endothelial dysfunctions [47]. Lifestyle changes such as poor food-habits, smoking, and other stressful conditions were reported as possible mediators of the association between overweight and PIH in women [48]. High CS rates in overweight or obese women may be related to slow progress of labor, increased labor induction, and associated co-morbid conditions such as diabetes mellitus, hypertension, and macrosomia [49]. The protective 
effect of obesity against severe perineal morbidity is speculated since increased adipose tissue in the pelvic floor increases the perineum ability to stretch and also widens the gap between the vaginal canal and rectum $[20,22]$. Perhaps, the women from high BMI group in our study delivered in a lithotomy position, and did not follow the appropriate pushing techniques during the second stage of labor, resulting in increased frequency of perineal injury. Previous studies have attributed the increased risk of PPH to less contractility of the uterine muscle $[27,50,51]$ and increased intervention during labor in obese women [52].

The present study has several strengths. The analyses were based on two prospectively collected cohorts of pregnant women, a reasonable number of sample sizes for each cohort, and a high number of contacts during antenatal and delivery periods for obtaining the outcome and related information. Further, the relevant socio-demographic variables were available for making adjustments to address confounding issues.

However, several limitations should be considered when interpreting the study findings. The BMI was assessed based on weight measurement at mean gestational weeks of 16.6 (1.1) and 12.9 (1.9), respectively, in the $\mathrm{MNCH}$ and PreSSMat cohorts. Due to limited weight gain before 20 weeks of gestation, this variation is unlikely to affect the measurement of malnutrition. A substantial proportion of women were excluded (25.3\%) from the analyses who participated in two cohorts. However, we did not find any significant difference in outcomes except CS (Table S5 in the Online Supplementary Document). This non-significant distribution of outcomes and also a very high participation rate (82\%) in the cohorts support the validity and representativeness of the study results to the population level, respectively. Like previous studies, we were not able to measure the amount of blood loss during the postpartum period. In both cohorts, we observed similar pattern of risk increase for PIH, CS, and perineal tear, but not for PPH. The subjective measurement of blood loss may compromise the internal validity of PPH's assessment in our study.

In this study, we investigated selected maternal health outcomes, which have a significant contribution to the health and survival of mothers and their offspring. PIH and PPH are reported as the major causes of maternal mortality in developing countries, including Bangladesh [53]. The burden of CS is also a public health challenge, as demonstrated by a recent increase in CS rate at the population level in South Asian countries. The BDHS reported that the national CS rate increased more than 5-fold in a decade, from 4\% in 2004 to $23 \%$ in 2014 [9]. It is also documented that CS may increase complications during subsequent pregnancies [54]. Perineal trauma is one of the most common morbidities in birthing women and is associated with shortand long-term health consequences such as increased hemorrhage, puerperal infection, urinary and fecal incontinence, and dyspareunia [55]. Further research should focus on understanding the causal link between high BMI and these pregnancy complications, and more studies are needed from low-income countries.

In conclusion, we have reported a double-burden of malnutrition in a rural area in Bangladesh. While the burden of underweight women has remained static, the proportion of overweight women has increased sharply in a short period, even in a rural community. Further, overweight women had increased proportions of PIH, CS delivery, perineal tear, and PPH. All these health conditions have significant short- and long-term health impacts on women and their offspring. The study results warrant appropriate counseling and preparedness tailored to women's nutritional status to prevent possible adverse health outcomes in women and children.

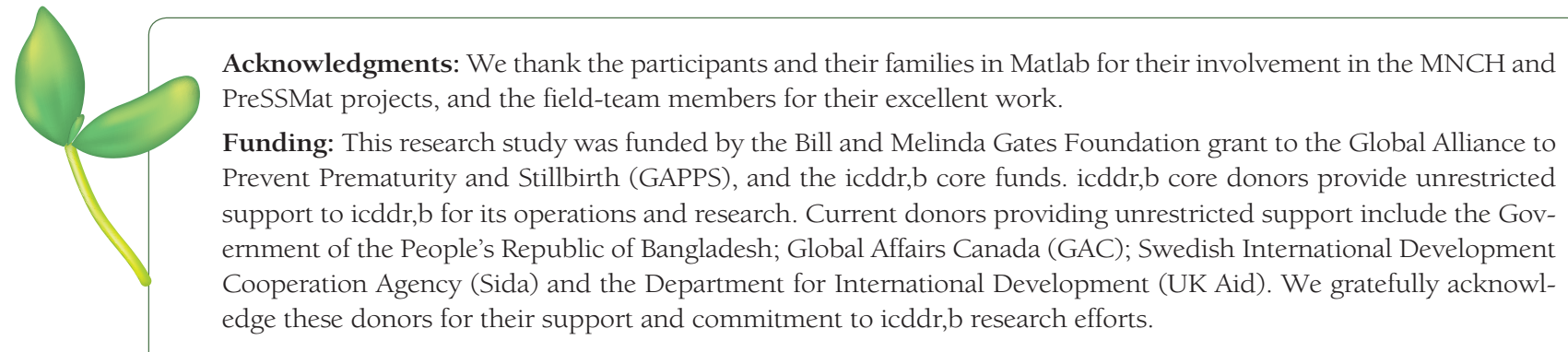

Authorship contributions: MR and AR contributed to the study concept and design. JP, SA and MR supervised the data collection. MR, SMR, SAE, and AR analyzed the data. MR prepared the initial draft of the manuscript. All authors contributed to the preparation of the database, interpretation of the results, and reviewed and approved the final version of the manuscript.

Conflict of interest: The authors completed the ICMJE Unified Competing Interest form (available upon request from the corresponding author), and declare no conflicts of interest.

\section{Additional material}

Online Supplementary Document 
1 Ramakrishnan U, Grant F, Goldenberg T, Zongrone A, Martorell R. Effect of women's nutrition before and during early pregnancy on maternal and infant outcomes: A systematic review. Paediatr Perinat Epidemiol. 2012;26:285-301. Medline:22742616 doi:10.1111/j.1365-3016.2012.01281.x

2 Wrottesley SV, Lamper C, Pisa PT. Review of the importance of nutrition during the first 1000 days: maternal nutritional status and its associations with fetal growth and birth, neonatal and infant outcomes among African women. J Dev Orig Health Dis. 2016;7:144-62. Medline:26279311 doi:10.1017/\$2040174415001439

3 Abdullah A. The double burden of undernutrition and overnutrition in developing countries: an update. Curr Obes Rep. 2015;4:337-49. Medline:26627492 doi:10.1007/s13679-015-0170-y

4 Black RE, Victora CG, Walker SP, Bhutta ZA, Christian P, de Onis M, et al. Maternal and child undernutrition and overweight in low-income and middle-income countries. Lancet. 2013;382:427-51. Medline:23746772 doi:10.1016/S01406736(13)60937-X

5 Baye K. The Sustainable Development Goals cannot be achieved without improving maternal and child nutrition. J Public Health Policy. 2017;38:137-45. Medline:28275250 doi:10.1057/s41271-016-0043-y

6 Development Initiatives. 2018 Global Nutrition Report: Shining a light to spur action on nutrition: Bristol, UK: Development Initiatives; 2018.

7 NCD Risk Factor Collaborations. (NCD-RISC). Trends in adult body-mass index in 200 countries from 1975 to 2014: a pooled analysis of 1698 population-based measurement studies with 19.2 million participants. Lancet. 2016;387:137796. Medline:27115820 doi:10.1016/S0140-6736(16)30054-X

8 Black RE, Allen LH, Bhutta ZA, Caulfield LE, de Onis M, Ezzati M, et al. Maternal and child undernutrition: global and regional exposures and health consequences. Lancet. 2008;371:243-60. Medline:18207566 doi:10.1016/S01406736(07)61690-0

9 NIPORT. Bangladesh demographic and health survey 2014. Dhaka, Bangladesh and Calverton, Maryland: National Institute of population research and training, Mitra and associates, and Macro International; 2014.

10 Devlieger R, Benhalima K, Damm P, Van Assche A, Mathieu C, Mahmood T, et al. Maternal obesity in Europe: where do we stand and how to move forward?: A scientific paper commissioned by the European Board and College of Obstetrics and Gynaecology (EBCOG). Eur J Obstet Gynecol Reprod Biol. 2016;201:203-8. Medline:27160501 doi:10.1016/j. ejogrb.2016.04.005

11 Lim CC. FRCOG, Mahmood T. Obesity in pregnancy. Best Pract Res Clin Obstet Gynaecol. 2015;29:309-19. Medline:25702971 doi:10.1016/j.bpobgyn.2014.10.008

12 Popkin BM, Adair LS, Ng SW. Global nutrition transition and the pandemic of obesity in developing countries. Nutr Rev. 2012;70:3-21. Medline:22221213 doi:10.1111/j.1753-4887.2011.00456.x

$13 \mathrm{Ng}$ M, Fleming T, Robinson M, Thomson B, Graetz N, Margono C, et al. Global, regional, and national prevalence of overweight and obesity in children and adults during 1980-2013: a systematic analysis for the Global Burden of Disease Study 2013. Lancet. 2014;384:766-81. Medline:24880830 doi:10.1016/S0140-6736(14)60460-8

14 Fuchs F, Senat M-V, Rey E, Balayla J, Chaillet N, Bouyer J, et al. Impact of maternal obesity on the incidence of pregnancy complications in France and Canada. Sci Rep. 2017;7:10859. Medline:28883521 doi:10.1038/s41598-017-11432-5

15 Afshin A, Forouzanfar MH, Reitsma MB, Sur P, Estep K, Lee A, et al. Health effects of overweight and obesity in 195 countries over 25 years. N Engl J Med. 2017;377:13-27. Medline:28604169 doi:10.1056/NEJMoal614362

16 Liu P, Xu L, Wang Y, Zhang Y, Du Y, Sun Y, et al. Association between perinatal outcomes and maternal pre-pregnancy body mass index. Obes Rev. 2016;17:1091-102. Medline:27536879 doi:10.1111/obr. 12455

17 Rahman MM, Abe SK, Kanda M, Narita S, Rahman MS, Bilano V, et al. Maternal body mass index and risk of birth and maternal health outcomes in low- and middle-income countries: a systematic review and meta-analysis. Obes Rev. 2015;16:758-70. Medline:26094567 doi:10.1111/obr.12293

18 Slack E, Rankin J, Jones D, Heslehurst N. Effects of maternal anthropometrics on pregnancy outcomes in South Asian women: a systematic review. Obes Rev. 2018;19:485-500. Medline:29349860 doi:10.1111/obr.12636

19 Smid MC, Vladutiu CJ, Dotters-Katz SK, Manuck TA, Stamilio DM. 374: Association between maternal obesity and major intraoperative complications. Am J Obstet Gynecol. 2016;214:S208-S. doi:10.1016/j.ajog.2015.10.415

20 Blomberg M. Maternal body mass index and risk of obstetric anal sphincter injury. BioMed Res Int. 2014;2014:395803. Medline:24839604 doi:10.1155/2014/395803

21 Drusany Starič K, Bukovec P, Jakopic K, Zdravevski E, Trajkovik V, Lukanovic A. Can we predict obstetric anal sphincter injury? Eur J Obstet Gynecol Reprod Biol. 2017;210:196-200. Medline:28061422 doi:10.1016/j.ejogrb.2016.12.029

22 Durnea CM, Jaffery AE, Gauthaman N, Doumouchtsis SK. Effect of body mass index on the incidence of perineal trauma. Int J Gynaecol Obstet. 2018;141:166-70. Medline:29178349 doi:10.1002/ijgo.12403

23 Meister MR, Cahill AG, Conner SN, Woolfolk CL, Lowder JL. Predicting obstetric anal sphincter injuries in a modern obstetric population. Am J Obstet Gynecol. 2016;141:5310e1-7.

24 Butwick AJ, Abreo A, Bateman BT, Lee HC, El-Sayed YY, Stephansson O, et al. Effect of Maternal Body Mass Index on Postpartum Hemorrhage. Anesthesiology. 2018;128:774-83. Medline:29346134 doi:10.1097/ALN.0000000000002082

25 Chaemsaithong P, Leung TY, Sahota D, Cheng YKY, Leung WC, Lo TK, et al. Body mass index at 11-13 weeks' gestation and pregnancy complications in a Southern Chinese population: a retrospective cohort study. J Matern Fetal Neonatal Med. 2019;32:2056-68. Medline:29301455 doi:10.1080/14767058.2018.1424824

26 Blomberg M. Maternal obesity and risk of postpartum hemorrhage. Obstet Gynecol. 2011;118:561-8. Medline:21860284 doi:10.1097/AOG.0b013e31822a6c59 
27 Fyfe EM, Thompson JM, Anderson NH, Groom KM, McCowan LM. Maternal obesity and postpartum haemorrhage after vaginal and caesarean delivery among nulliparous women at term: a retrospective cohort study. BMC Pregnancy Childbirth. 2012;12:112. Medline:23078042 doi:10.1186/1471-2393-12-112

28 Scott-Pillai R, Spence D, Cardwell CR, Hunter A, Holmes VA. The impact of body mass index on maternal and neonatal outcomes: a retrospective study in a UK obstetric population, 2004-2011. BJOG. 2013;120:932-9. Medline:23530609 doi:10.1111/1471-0528.12193

29 Ovesen P, Rasmussen S, Kesmodel U. Effect of prepregnancy maternal overweight and obesity on pregnancy outcome. Obstet Gynecol. 2011;118:305-12. Medline:21775846 doi:10.1097/AOG.0b013e3182245d49

30 Schummers L, Hutcheon JA, Bodnar LM, Lieberman E, Himes KP. Risk of adverse pregnancy outcomes by prepregnancy body mass index: a population-based study to inform prepregnancy weight loss counseling. Obstet Gynecol. 2015;125:133-43. Medline:25560115 doi:10.1097/AOG.0000000000000591

31 Chowdhury MAB, Adnan MM, Hassan MZ. Trends, prevalence and risk factors of overweight and obesity among women of reproductive age in Bangladesh: a pooled analysis of five national cross-sectional surveys. BMJ Open. 2018;8:e018468. Medline:30030307 doi:10.1136/bmjopen-2017-018468

32 Khan MN, Rahman MM, Shariff AA, Rahman MM, Rahman MS, Rahman MA. Maternal undernutrition and excessive body weight and risk of birth and health outcomes. Arch Public Health. 2017;75:12. Medline:28174626 doi:10.1186/ s13690-017-0181-0

33 Yazdani S, Yosofniyapasha Y, Nasab BH, Mojaveri MH, Bouzari Z. Effect of maternal body mass index on pregnancy outcome and newborn weight. BMC Res Notes. 2012;5:34. Medline:22251801 doi:10.1186/1756-0500-5-34

34 Rahman A, Moran A, Pervin J, Rahman A, Rahman M, Yeasmin S, et al. Effectiveness of an integrated approach to reduce perinatal mortality: recent experiences from Matlab, Bangladesh. BMC Public Health. 2011;11:914. Medline:22151276 doi:10.1186/1471-2458-11-914

35 Murphy MS, Hawken S, Cheng W, Wilson LA, Lamoureux M, Henderson M, et al. External validation of postnatal gestational age estimation using newborn metabolic profiles in Matlab, Bangladesh. eLife. 2019;8:e42627. Medline:30887951 doi:10.7554/eLife.42627

36 World Heath Organization. Report of a WHO consultation, World Health Organ Technical Report Series. Geneva: WHO; 2000.

37 World Health Organization. Integrated Management of Pregnancy and Childbirth. Pregnancy, Childbirth, Pospartum and Newborn Care: A guide for essential practice. Geneva: WHO (2015), ISBN: 9789241549356.

38 Short VL, Geller SE, Moore JL, McClure EM, Goudar SS, Dhaded SM, et al. The relationship between body mass index in pregnancy and adverse maternal, perinatal, and neonatal outcomes in rural India and Pakistan. Am J Perinatol. 2018;35:844-51. Medline:29365329 doi:10.1055/s-0037-1621733

39 Ehrenthal DB, Jurkovitz C, Hoffman M, Jiang X, Weintraub WS. Prepregnancy body mass index as an independent risk factor for pregnancy-induced hypertension. J Womens Health (Larchmt). 2011;20:67-72. Medline:21194273 doi:10.1089/jwh.2010.1970

40 Van Der Linden EL, Browne JL, Vissers KM, Antwi E, Agyepong IA, Grobbee DE, et al. Maternal body mass index and adverse pregnancy outcomes: A Ghanaian cohort study. Obesity (Silver Spring). 2016;24:215-22. Medline:26574712 doi:10.1002/oby.21210

41 Ghamdi T, Hanouf Al Thaydi A, Chamsi A, Al Mardawi E. Incidence and risk factors for development of third and fourth degree perineal tears: A four year experience in a single Saudi Center. J Women Health Care. 2018;07:1000423. doi:10.4172/2167-0420.1000423

42 National Accounts Statistics. Bangladesh Bureau of Statistics, Statistics and Informatics Division, Ministry of Planning. Available: http://bbs.portal.gov.bd/sites/default/files/files/bbs.portal.gov.bd/page/057b0f3b_a9e8_4fde_b3a6_ 6daec3853586/National\%20Accounts_Book_2017-18.pdf. Accessed: 2 February 2020.

43 Mohsena M, Hossain M, Chakraborty B, Bayes A, Rahman ANM. Fragile Environment, Seasonality, and Maternal and Childhood Undernutrition in Bangladesh. J Biosoc Sci. 2018;50:579-603. Medline:28918764 doi:10.1017/ S002193201700044X

44 Bodnar LM, Ness RB, Harger GF, Roberts JM. Inflammation and triglycerides partially mediate the effect of prepregnancy body mass index on the risk of preeclampsia. Am J Epidemiol. 2005;162:1198-206. Medline:16269584 doi:10.1093/ aje/kwi334

45 Jeyabalan A. Epidemiology of preeclampsia: impact of obesity. Nutr Rev. 2013;71 Suppl 1:S18-25. Medline:24147919 doi:10.1111/nure.12055

46 Madan JC, Davis JM, Craig WY, Collins M, Allan W, Quinn R, et al. Maternal obesity and markers of inflammation in pregnancy. Cytokine. 2009;47:61-4. Medline:19505831 doi:10.1016/j.cyto.2009.05.004

47 Spradley FT, Palei AC, Granger JP. Increased risk for the development of preeclampsia in obese pregnancies: weighing in on the mechanisms. Am J Physiol Regul Integr Comp Physiol. 2015;309:R1326-43. Medline:26447211 doi:10.1152/ ajpregu.00178.2015

48 Bodnar LM, Catov JM, Klebanoff MA, Ness RB, Roberts JM. Prepregnancy body mass index and the occurrence of severe hypertensive disorders of pregnancy. Epidemiology. 2007;18:234-9. Medline:17237733 doi:10.1097/01. ede.0000254119.99660.e7

49 Wispelwey BP, Sheiner E. Cesarean delivery in obese women: a comprehensive review. J Matern Fetal Neonatal Med. 2013;26:547-51. Medline:23130683 doi:10.3109/14767058.2012.745506

50 Hollowell J, Pillas D, Rowe R, Linsell L, Knight M, Brocklehurst P. The impact of maternal obesity on intrapartum out- 
comes in otherwise low risk women: secondary analysis of the Birthplace national prospective cohort study. BJOG. 2014;121:343-55. Medline:24034832 doi:10.1111/1471-0528.12437

51 Zhang J, Bricker L, Wray S, Quenby S. Poor uterine contractility in obese women. BJOG. 2007;114:343-8. Medline:17261121 doi:10.1111/j.1471-0528.2006.01233.x

52 Rossen J, Okland I, Nilsen OB, Eggebo TM. Is there an increase of postpartum hemorrhage, and is severe hemorrhage associated with more frequent use of obstetric interventions? Acta Obstet Gynecol Scand. 2010;89:1248-55. Medline:20809871 doi:10.3109/00016349.2010.514324

53 Bangladesh Maternal Mortality and Health Care Survey 2016: Preliminary Report. Dhaka, Bangladesh, and Chapel Hill, NC, USA: NIPORT, icddr,b, and MEASURE Evaluation.

54 Sandall J, Tribe RM, Avery L, Mola G, Visser GH, Homer CS, et al. Short-term and long-term effects of caesarean section on the health of women and children. Lancet. 2018;392:1349-57. Medline:30322585 doi:10.1016/S0140-6736(18)31930-5

55 Aguiar M, Farley A, Hope L, Amin A, Shah P, Manaseki-Holland S. Birth-related perineal trauma in low- and middle-income countries: A systematic review and meta-analysis. Matern Child Health J. 2019;23:1048-70. Medline:30915627 doi:10.1007/s10995-019-02732-5 